\title{
4 Community-Driven Approaches to Open Source Archaeological Imaging
}

\subsection{Introduction}

During the previous decade the use of two-dimensional (2D) and three-dimensional (3D) imaging techniques in Archaeology has developed at great speed, from being virtually unknown to being a conventional part of the archaeological toolkit. Imaging techniques are frequently used for the documentation and analysis of archaeological material. This trend has been facilitated by the falling costs of devices and software which allow imaging data to be captured, processed and analysed. However, in spite of these rapid declines in cost, these tools remain inaccessible to large parts of the archaeological research community. Digital imaging techniques often remain costly in comparison to traditional forms of archaeological recording and analysis. The acquisition of hardware and software can represent an unrealistic level of investment for less well funded groups working within research, voluntary or commercial sectors. These financial barriers are further compounded by limitations on expert knowledge required to capture and effectively use these data within research methodologies.

The advent of free and open source imaging software has the capacity to disrupt this pattern. Techniques such as Reflectance Transformation Imaging (RTI), photogrammetry, and multi-spectral imaging can now be undertaken with little or no investment in additional equipment (Downing et al., 2012; Jordan and Angelopoulou, 2010). However despite the availability of these tools there remain considerable barriers to uptake and consistent use. Methodologies are often written for audiences with a degree of expert knowledge which effectively precludes use by those with little or no specialist knowledge of imaging. Even where this is not the case, as groups often remain unaware of imaging technologies or the potential impact which they might have for their work.

This paper will argue that the proliferation of open and inexpensive technology represents a unique opportunity to expand and to normalise the use of imaging techniques which have typically been seen as inaccessible and requiring expert knowledge. Furthermore it will argue that the use of open source software within archaeology can, if properly supported, lead to the development of tools which more effectively

Gareth Beale: University of York, York, UK

Nicole Beale:University of Southampton, Southampton, UK 
meet the needs of archaeological researchers. We will argue that in order to ensure that these techniques become accessible as well as available archaeologists must develop methodologies and strategies for distribution which engage technical non-specialists within the archaeological research community including those from voluntary, commercial and academic research backgrounds.

Limited uptake of digital imaging techniques by technical non-specialists has not only inhibited the spread of these tools but has also prevented their potential versatility from being realised. The paper will draw upon two case studies which have sought to expand the use of low-cost and free imaging techniques amongst research communities with little or no experience of archaeological computing methodologies. It will argue that in addition to expanding the community of researchers with the skills necessary to use these techniques, these efforts have also altered and extended existing perception of the value and possible applications of these tools. In part, this has been due to the development of methodologies which allow non-specialist users to influence the development of open source software.

\subsubsection{Using Case Studies}

The case studies detailed in the paper are the Re-reading the British Memorial Project (OuRTI) and the Basing House Community Archaeology and Technology (CAT) Project. The OuRTI project is a community documentation project which aims to spread the use of RTI amongst amateur and professional researchers already engaged in the documentation of British cemeteries and graveyards. The emphasis of the project has been on the development of accessible methodologies and sustainable organisational structures which can be used to spread use of the technique without the need for ongoing expert support. The project builds upon existing networks of expertise and aims to normalise the use of RTI as a conventional documentation and analysis tool.

The Basing House CAT Project is a research excavation at Basing House in Hampshire which incorporates researchers from a range of organisations including Hampshire County Council, the University of Southampton, Winchester School of Art, Basingstoke Archaeological and Historical Society and the University of York. In conjunction with students, volunteers and professional archaeologists the project aims to develop innovative and experimental applications for low cost and open source imaging technologies. The project places an emphasis on skills sharing and encourages researchers from all backgrounds to learn how to use digital imaging technologies as well as developing conventional archaeological skills.

Each of these projects involves the development of distinctive methodologies which are enriched through the addition of imaging technology presented in an accessible way. Pre-existing expertise and diverse perspectives on the use of technology contributes towards the development of methodologies which maximise the effectiveness of technologies and often leads to them being used in unanticipated and creative 
ways. Before discussing the specific methodological approaches adopted in each of these projects the following section will discuss the impact which different models of software development have upon the effective production, distribution and use of digital imaging tools within archaeology.

\subsection{Technological Innovation: New Development Models}

The open source and the free software movements have presented a challenge to conventional modes of technological development. Models of software development can be divided into four broad categories. Proprietary software (of which most commercial software is a part) can be bought for individual or group use, the software is made available under license to the user, and the developer maintains a certain level of control over the program. Shareware is generally available for free initially, but with restrictions on usage so that the software must be purchased to gain access to all functionality, or to continue to use it at the end of a period of trialling. Freeware is released freely but the source code is not made available, there are no development opportunities and the software is used 'as is'. Open source is available freely at source code level and can be developed and built on as well as reused for other programs. Free software must remain free no matter the re-use and re-development activities.

For software to be open source much more is required than the release of source code openly. Free software presents an added level of complexity as open source software licenses do not necessarily guarantee that software will be free. There are criteria as defined by the Open Source Initiative (OSI) from whom the open source license trademark is received. In addition to the source code being made freely available, licenses for open source software must not restrict redistribution and cannot charge for reuse. If software is produced which is derived from an earlier product then the elements of the derivative work which are re-used retain the original license. Even through redistribution, no additional licenses are required. Modification of source code is allowed, but only if permitted by the license, however, the license cannot prevent the use of a program away from the original product release, this means that all parties involved in redistribution have the same rights, the license also cannot include restrictions on other software that might be included in future distributions, and all releases must be technology-neutral, without restrictions on technology type or style (Open Source Initiative, n.d.).

Open source development would seem to represent a great opportunity for archaeology; allowing for collaborative software development which is often less resource intensive than building a product from scratch. There are alternative models for software design and release, such as freeware and shareware which offer alternative modes of acquiring low cost software but open source is unique in its ability to provide the user community with a genuine way to contribute to the development of the program.

However, in order to understand the impact of these development models upon 
archaeology it is important to consider the nature of the development communities and the nature of the products which are produced. The rhetoric surrounding open source software development and release tends to emphasise the altruistic nature of releasing software in this way (Hars and $\mathrm{Ou}, 2001$ ). There is also a regular emphasis on the democratising effects of source code release and the potential for on-going collaborative development (Von Hippel and Von Krogh, 2003; Huizingh, 2011). However, it would be a mistake to assume that the use of open source software necessarily represents an inexpensive solution. Open source development increases the connection between the systems engineering, process and management (Sage and Rouse, 2009, p. 4). But there is still much that can be done to improve the link between the end user and the development of the technology. This disconnection often means that additional costs are incurred where open source tools are implemented within archaeological research methodologies. These costs can consist of time and resources spent familiarising a research teams with software which has not been subject to the same degree of user testing that a commercially produced product might have been. Alternatively, it may be necessary to modify software in order to prepare it for use in an archaeological setting.

Despite the seemingly public facing nature of an 'open' release of software, using platforms such as GitHub and sourceforge, developers of open source software are not necessarily better equipped to provide explanatory notes to accompany software releases. Open source software can often be even less accessible to non-computer specialist users than software developed using other development models. A model of software development and release that results in a product marketed at paying customers will have a greater emphasis on usability and on clear statements of purpose for users. The financial sustainability of developers using this model is often dependent upon the mass uptake of software within a targeted community. The key to the adoption of new software by archaeology is the availability of use case instances. Software which is shown to be useful is far more likely to achieve widespread use than software which is functional but largely unknown beyond technical specialists. This can even be the case with software and indeed technologies that develop a negative reputation for complicated user interfaces or expensive hardware requirements.

Open source development has huge potential to deliver tools which are built for use within an archaeological setting and developed with the requirements of archaeologists in mind. However, the fact that development takes place within an open framework does not necessarily ensure that the process of development or the end product is any more accessible to non-specialist users than the proprietary alternatives. 


\subsection{Introducing the Methodology}

The case studies covered in the second part of this chapter make use of a variety of low cost and free technology solutions for computational imaging. Highlight RTI and photogrammetry are two methods that make up a part of the suite that was used.

\subsubsection{Reflectance Transformation Imaging}

Highlight RTI is a form of computational photography which uses polynomial texture mapping (PTM) in order to create an interactive file within which an object can be viewed with a moveable light source. The process is relatively straightforward and requires only a digital camera for which the aperture and focus can be set manually, a moveable light source, such as a flash with a remote trigger or a torch, and a reflective sphere. The lowest cost option for this is a black or red snooker ball. A series of photographs are taken with a static camera which has been set to allow very little ambient light into the image, relying instead on the remote light source. The images are taken one after another with the light source in a different location each time, in order to have a collection of photographs with the light projecting onto the object from a wide range of angles. The reflective sphere must also be in the photographs, but static, remaining in the same location throughout. In each photograph, the reflective sphere will show a highlight from the light source.

The open source software, RTIBuilder uses the location of this highlight to create the output file. RTIViewer software opens the RTI file and allows the user to interact with the results, producing a variety of visualisations from the data. These include the production of a normals visualisation and also the use of specular enhancement or diffuse gain to provide images with views of edges or surface details not apparent in a conventional raking light photographs.

\subsubsection{Photogrammetry}

Photogrammetry is a means of calculating 3D geometry based upon a series of still images of an object or scene. Recording for a photogrammetric model is relatively straightforward. Some parameters must be set on the digital camera to ensure calibration before collecting photographs, these include the focal length and format aspect ratio, and planning to compensate for lens distortion is important. Photogrammetric models can be created by taking a series of photographs of an object or scene where the distance of the camera from the item is maintained, but the camera is moved around to cover as much of the surface area as possible. The photographs must have a substantial overlap. The chosen software compiles the images together to automatically 
create a 3D mesh from those images. There are various options for photogrammetry processing, both free and commercial.

\subsubsection{Assessing the Benefits of Open Source Imaging Methodologies}

The open source software solutions are often cheaper in cost than their proprietary counterparts, but this is not necessarily the only cost involved. If we consider the example of three-dimensional data capture and processing, in one of the case studies to be discussed in this chapter, a combination of Highlight RTI with photogrammetry is used in replacement of a laser scanner. There are several open source solutions for the compiling of photographs to create 3D meshes for photogrammetry and remote sensing of small and large objects (from coins to building facades), and so results are often very varied. Despite hardware and software solutions often being complicated to install and to use, these methods are being used increasingly by archaeologists, often in lieu of the availability of a laser scanner, as the data capture requires equipment that is generally available to the archaeologist, such as a digital SLR camera.

There are benefits and disadvantages to using both approaches. Laser scanners are accurate and the results are reliable, however recording even the smallest object is a time consuming exercise. Photogrammetry on the other hand is a method which produces a less detailed 3D mesh than laser scanner results and is often unreliable, but recording using a camera is much faster than using a laser scanner. In addition to this, when used in conjunction with Highlight RTI, which produces highly accurate surface imaging, although not currently linked to 3D meshes, this is less problematic for many projects' requirements. The two approaches have differing suitability depending on the situation, but one selling point of photogrammetry combined with Highlight RTI over laser scanners is the price tag. A terrestrial laser scanner is a costly piece of equipment, even when rented for short time periods there is a substantial cost that must be considered. Photogrammetry combined with Highlight RTI, because of the open source and also freeware options for data processing, is far cheaper. The methods require only a digital camera for data capture. However, the cost for photogrammetry with highlight RTI is high in other ways. Open source software options are often less user friendly than costly proprietary alternatives, and the software for Highlight RTI is an example of this.

RTIBuilder is the open source software used for Highlight RTIs. The software is released under GNU General Public License, which means that it is free software. This is slightly different to open source software. The OSI has accepted licenses, such as the Reciprocal Public License 1.5 (RPL-1.5) which allow for non-free software. This license would not qualify under the definition of free software from the Free Software Foundation (Free Software Foundation, 2012). The license used for RTIBuilder is a free software license, and so there is more freedom for development. RTIBuilder was funded and developed by a team at the Universidade do Minho in Braga, Portugal, with ad- 
ditional funding and input from Cultural Heritage Imaging. The current release of the software (2.0.2) incorporates HSHFitter (GNU General Public License version 3, copyright University of California, Santa Cruz and Cultural Heritage Imaging 2007 - 2009). RTIBuilder requires either HSHFitter or PTMFitter (Binary Code License Agreement, by Hewlett Packard) to work. PTMFitter is not compatible with the GNU license and so must be downloaded separately.

As with many open source software, RTIBuilder has been amended and improved over time since its inception more than five years ago, and consequently there are numerous steps and requirements for the processing of an RTI. The user manual currently available to download on the Cultural Heritage Imaging website is over 20 pages in length (Schroer and Bogart, 2011). The instructions are excellent and the steps in the manual are easy to follow. However, a manual of this size and complexity for one part of the process can be a daunting discovery for an enthusiastic computational photography beginner.

\subsection{Community Methodologies and Technological Uptake}

The availability of a technology and the fact that it has the technical capability to fulfil a specific methodological role does not ensure its adoption by members of the archaeological research community. It is necessary also to ensure that available tools are accessible to the community in question and that they are perceived to be relevant. In terms of the development of computational tools the concepts of availability, accessibility and relevance are intimately connected.

\subsubsection{Development Model Alternatives}

A key failure in the uptake of technology is matching the need of the user community to the technology itself, even in projects using participatory design for agile software development with grounding in complex adaptive systems theory, end-users can become a secondary consideration (Kautz, 2011). This can lead to a disconnect between users and developers, particularly in the open source community where users tend to have a higher level of computational knowledge than those using a more 'out of the box' type of software or hardware solution.

Archaeology has traditionally embraced new technologies, and is an area within which much innovation has occurred driven by the user community rather than the developer community (Sillar and Tite 2000; Wheatley et al. 2002, p. 2). In a world where these definitions are blurring, we find ourselves at a crossroads between continuing as consumers of technology developed within other sectors, or as producers of technology within our own sector. Open source makes the latter possible, but there are 
still substantial hurdles that must be overcome in order for the full potential of open source software and hardware development in archaeological imaging to be realised.

There are additional requirements to the technology for a change to occur. Up until now, there has been a focus on computational photography experts within archaeology collaborating with or contributing to computational photography experts outside of the sector to develop the technology. Archaeology has long had a tradition of involvement from amateurs (Kelley, 1963; Levine, 2003; Taylor, 1995; Moshenska, 2010). There is potential user group and development community that has as of yet not been mobilised for the improvement of archaeological imaging. Community methodologies can engender new forms of technological practice.

A common frustration between researchers and developers has been the failure of transfer of ideas from one to the other (Suchman, 1993, p. 23). The open source software model offers a way to surmount this problem by placing the emphasis on the research, development, testing and redevelopment of software by all of the community. In this way it is possible to ensure that the software under development does not only have the necessary functionality but that it also reflects the desires and requirements of the user community. This can include factors such as the use of appropriate vocabulary, the layout of the interface or the ability to annotate data. These factors are what ensure that a piece of software is not just functional and available but also accessible and relevant to the community for which it is being developed. GitHub, one of the major platforms for the releasing of open source software code is popular as a space for the development of software from an idea to a product as it facilitates collaboration. Used appropriately these collaborative platforms and ways of working can help to ensure the relevance and usability of source code once it is released.

Community based methodologies that allow non-experts to contribute more readily to product development offers a solution to improving the gap between research and product. The open source development model provides a scaffold upon which to build this methodology, but additional components are needed to ensure successful uptake of open source solutions both within and outside of professional archaeology.

\subsubsection{Ensuring Meaningful Software Access}

What is needed for successful uptake of any new technology is the possibility for development not just of the source code, but of the methodology surrounding the adoption and adaption of the technological solution. An example of this is PTMFitter; the software which underpins RTI. The uptake of the technique of PTM has been driven by the cultural heritage sector, in particular by Cultural Heritage Imaging (CHI), which has forged a new path for the use of PTM as part of the RTIBuilder and RTIViewer software (Mudge et al., 2010).

Not only have the organisation worked with other communities to develop the software, but they have also written handbooks for data capture and processing, and 
have published papers encouraging the academic and commercial community to use the method. CHI has created numerous 'How To' videos and delivered many training workshops to archaeologists, historians, archivists and others. PTMFitter as a standalone open source option for computational imaging is not enough to lead to the uptake of RTI as a key part of computational imaging for the area of archaeology. RTIBuilder represents a substantially more user friendly solution to the use of polynomial texture mapping for the recording of objects. The development of RTI builder in conjunction with the anticipated user community has helped to ensure that the software is appropriate for use within the context of cultural heritage. However it has been through the development of an RTI user community within the cultural heritage sector that the technique has truly developed into a popular research tool.

There are also open source and free software solutions for photogrammetry. ArchTeam's ArcheOS (an archaeological operating system using Debian Squeeze) which incorporates Python Photogrammetry Toolbox, or VisualSFM from the University of Washington offer open source solutions for the creation of photogrammetric models from images, but the installation and use of these options is complicated and requires computational experience. There are alternative options, such as the Arc3D web-service produced by the Epoch Network of excellence, but results from this are varied and tend to need substantial reworking. What is needed now is a pipeline for the use of a suite of options to record objects, which will open up the potential of computational imaging to outside of the small group of experts who currently make use of the technique.

Non-professional archaeology communities can allow us to question conventionalised narratives relating to the function, value and purpose of technology. As we shall see, it is important that we develop methodologies which allow us to take these groups into account. A flexible methodology is required to allow for a more inclusive user community to develop.

\subsection{Case Study One: Basing House Community, Archaeology and Technology Project}

The Basing House CAT project is a multi-organisational research excavation carried out by paid staff, archaeology and history student, and volunteers. The project consists of a summer fieldwork season during which excavations are carried out on the remains of the multi-phase site of Basing House, a Tudor period fortified house built on top of a Medieval motte and bailey castle with keep. The house was partially destroyed after years of sieges during the English Civil War (Allen et al., 2013). Material has emerged from the site which suggests that occupation pre-dates the earliest Norman phase evident in the standing remains.

The Basing House CAT project has also offered a unique environment within 
which to develop and to refine the use of imaging technology. Unlike the OuRTI project, activity at Basing House is confined to a brief four week field season each summer. During this time fifty staff, students and volunteers can be on site at any time. During the 2013 season at least half of these team members were trained in the use of Highlight RTI and photogrammetry (Figure 4.1).

One of the core objectives of the Basing House CAT project is to promote methodological innovation within field archaeology, particularly in the use of digital imaging. Project members are encouraged throughout their time onsite to consider how imaging techniques might be usefully employed within their work. The excavation is run on a rota system with all participants having the opportunity to excavate but also to contribute to other elements of the project including building survey, the documentation of standing remains, public outreach and the documentation of the entire project as it proceeds. The latter activity takes many forms including a project blog which is updated daily during the field season, a photographic record of the excavations and work undertaken in collaboration with an artist in residence.

The project represents an ideal setting for the intensive development of experimental imaging methodologies. As well as the variety of activities within which imaging techniques can be applied the project also benefits from the fact that the onsite team have an enormous variety of experience and specialisms. Team members conventionally include archaeologists, historians and artists but volunteers with professional careers outside of academia or commercial archaeology contribute a vast range of additional skills and experience.

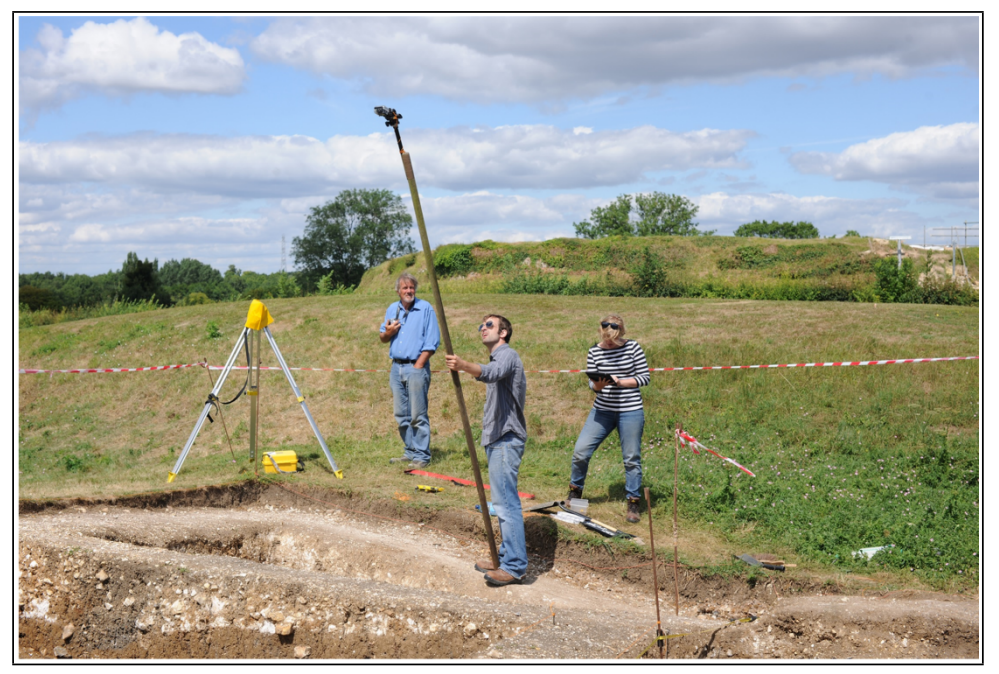

Figure 4.1: Basing House CAT project team members use a GoPro camera, along with the remote controlling iPad app, to photograph the trenches at the end of the excavation season. The images were used to create a photogrammetric model of the excavation 


\subsubsection{Skills Sharing}

The working environment of the fieldwork project coupled with the diversity of skills and experience present within the excavation team mean that the sharing of skills is inevitable. While engaged in other activities team members are encouraged to think creatively about how they could apply the skills learnt elsewhere on the project to the situation within they find themselves. As a consequence methodological innovation is not confined to the use of imaging technologies.

The mixed skill sets coupled with this approach mean that unexpected approaches to the use of technology are a regular occurrence (Beale et al., 2013). The situation helped to ensure that where innovations occur they are rapidly refined and developed in response to expert advice from other team members. This helped to encourage relatively inexperienced team members to suggest new approaches and helped to ensure that these suggestions were often developed into effective methodological strategies. One example of this followed a group visit to the village church of Old Basing very close to the excavation led by a church archaeologist and team member. An undergraduate student proposed that the techniques being applied to digitally image the site might also be used to document signs of English Civil War activity in the church including iconoclastic damage to statues. This suggestion of this project (which should be completed during the coming field season) came about as a result of the students' knowledge of the imaging techniques used onsite but also as a result of expert advice from an experienced specialist.

\subsubsection{Experimental Atmosphere}

The encouraging of experimental approaches to technology, while not always successful has regularly led to innovative and highly successful trials. These have included the use of Highlight RTI to document sections in addition to the use of conventional section drawings, the use of Highlight RTI to assess the difference between original Tudor bricks and 19th Century replacements. RTI as a means of documenting sections was championed by an experienced volunteer excavator who saw the potential benefits of this recording technique after having seen demonstrations of RTIs of small archaeological objects. Highlight RTI images of sections enabled the detailed documentation and subsequent analysis of sections in addition to the use of conventional drawings and photographs. Under certain circumstances, especially situations within which objects and complex features were evident in the sections, this technique proved to be a valuable aid to presentation and subsequent explanation.

The use of Highlight RTI to differentiate between 19th century bricks and Tudor originals was suggested by an undergraduate student who had particularly enjoyed learning to use the technique and was tasked with finding innovative applications. The project is still underway and so the effectiveness of the technique in this context 
is not yet known. However, the fact that comparatively inexperienced students were addressing complex conservation issues and considering how new technologies might be employed in this setting is noteworthy in its own right.

Finally and perhaps most significantly was the use of RTI to document Roman Coins found on the Basing House excavation. The desire to identify these coins, several of which were badly corroded led to multiple attempts by different project members to produce effective visualisations using Highlight RTI and photogrammetry. The activity quickly became playfully competitive leading to extremely high quality visualisations and identification and of the coins. The major benefit though came from the communication between project members as they sought to produce high quality visualisations. An emphasis on problem solving rather than abstract acquisition of another new skill meant that participants very quickly refined their technique and familiarise themselves with the nuances and challenges of 3D and 2D imaging techniques in a fieldwork scenario.

\subsubsection{Basing House Conclusions}

Projects like Basing House CAT provide an opportunity to develop imaging methodologies within the context of a broader field archaeology project. This helps to ensure that methodological innovations are driven by the demands of the research process and not solely by the capabilities of the technology. Within an atmosphere of diverse skills and experience it would quickly become apparent if a new approach was ineffective or unnecessary allowing the quality of new approaches to be rapidly honed. Subsequent to the field season lessons learned were integrated into new methodologies which can be used in future seasons and distributed to other field archaeology teams. As well as allowing the development of methodological approaches, the experimental use of imaging techniques within this setting also produced a list of weaknesses in software which have subsequently been incorporated into plans for on-going software development.

\subsection{Case Study Two: Re-Reading the British Memorial}

The OuRTI project came about in 2012 following the design and delivery of a Lifelong Learning module, Urban Archaeology, by Gareth Beale and Nicole Beale at the University of Southampton (Figure 4.2). This module aimed to introduce adult learners to the potential of using archaeological techniques to learn more about their local heritage environment. Over twelve weeks, the course introduced and reviewed numerous technologies which could be used to find out about a series of themes relating to urban archaeology, such as the built environment, industrial heritage, cultural diversity, and family links. Throughout the module, the focus was on providing realistic options 
for learners to adopt for their own research. Learners came from all over the county of Hampshire and were from varied backgrounds, the course coordinators therefore had to ensure that the technologies and methodologies being taught were available to individuals with no connection with academic, third sector, or commercial archaeological organisations, and with little or no access to expertise in the technology being introduced. The majority of adult learners at the University of Southampton do return over a period of years to modules within the same discipline, but continued access to University resources is not a given. Urban Archaeology therefore relied upon low cost or free technology solutions. This often meant that software was open source or free software and that hardware was not the most recent incarnation of that particular technology. Part-way through the module, the lecturers introduced computational imaging for archaeology. The concept captured the imagination of the class, and ideas and technologies were returned to over the following weeks. There seemed to be a significant interest in the ways that computational imaging could be used by amateur archaeologists not just for dissemination of findings but for recording and interpretation.

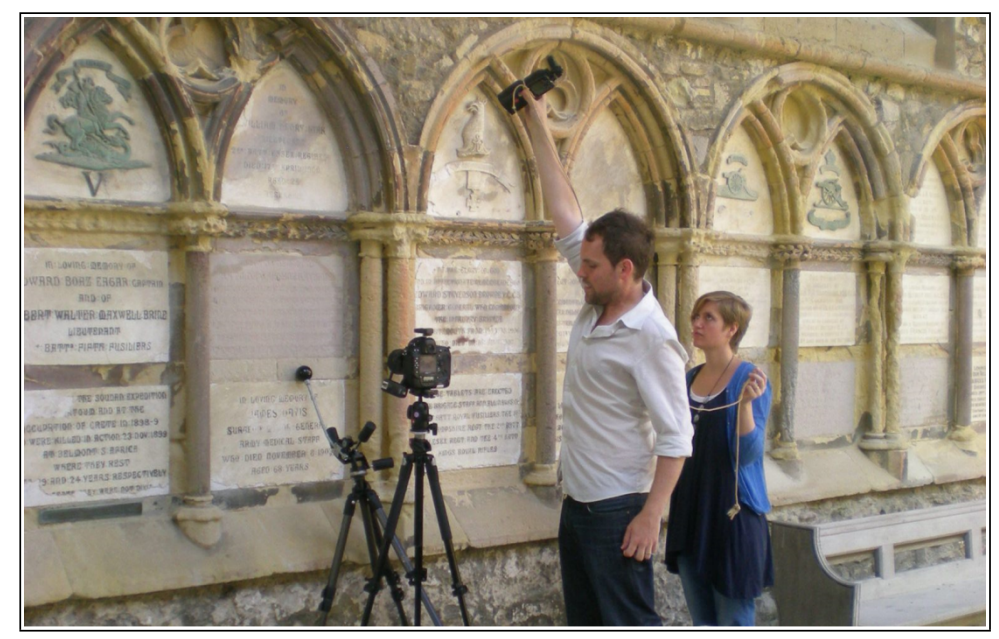

Figure 4.2: OuRTI team members giving a Highlight RTI demonstration at Royal Garrison Church, Portsmouth

The module had an emphasis on practical demonstration and on hands-on learning, and so as part of the computational imaging tutorial a workshop was held at a local church. Churches are rich case studies for an introduction to the principles of computational imaging for recording. They are sites full with artefacts and architecture, and these bring with them challenges that are present across the discipline. The church had been identified earlier by the module team as being a useful test bed for a suite of 
technologies being used by the Archaeological Computing Research Group and had been visited a number of times by the module conveyors. A workshop had been organised for the history group aligned with the church to introduce RTI as a method for interpreting badly eroded and damaged headstones in the church graveyard. The workshop had been very popular and had led to a surveying project with the group. Following the Urban Archaeology and the training that had been delivered at the church to the local history group, a number of challenges and research questions had been identified.

A team was formed to begin a project that would test the usefulness of RTI and other open source or free software solutions for the recording of graveyards, cemeteries and church memorials by special interest groups through a series of workshops (Figure 4.3). The project won a small amount of Digital Humanities funding from the University of Southampton to facilitate a pilot of case study identification and workshop delivery (Beale and Beale, 2012).

The OuRTI project aims to facilitate the use of computational imaging techniques for the recording and interpretation of church memorials. Since the project's inception, the team have worked with numerous local history groups and special interest groups to record graveyards and memorials inside churches using technologies such as RTI and photogrammetry. The project has also incorporated additional community requirements as have been requested by specific groups, such as surveying techniques and data management.

\subsubsection{Adaptive Methodologies}

OuRTI involves diverse communities of expertise, and this is a key strength of the approach established early on in the project. Generally, a case study will begin with contact between the project team and a group of individuals working alongside the church staff to carry out a specific research project at the church. This can range from attempting to identify particular individuals' resting place within a graveyard to carrying out a full-scale recording survey of a church's interior. A key element of the project is that there is no control over pre-existing structure of organisations within each case study. With each case study, the hierarchy must be respected, and the objectives for that particular case study must be negotiated. All case studies agree to allow the data collected as part of the project be copied and archived by the OuRTI team. This ensures that there is a comprehensive record of the data, but also that there is a collection of RTIs that showcase the potential of the technology and can be used as resource for the study of church memorials, as well as being useful for the teaching of processing archaeological imaging data.

For every case, the project team meets with church representatives and gives a demonstration of the technologies available. The consultation period is essential to the working of the project, as each case study has a different need and the techno- 


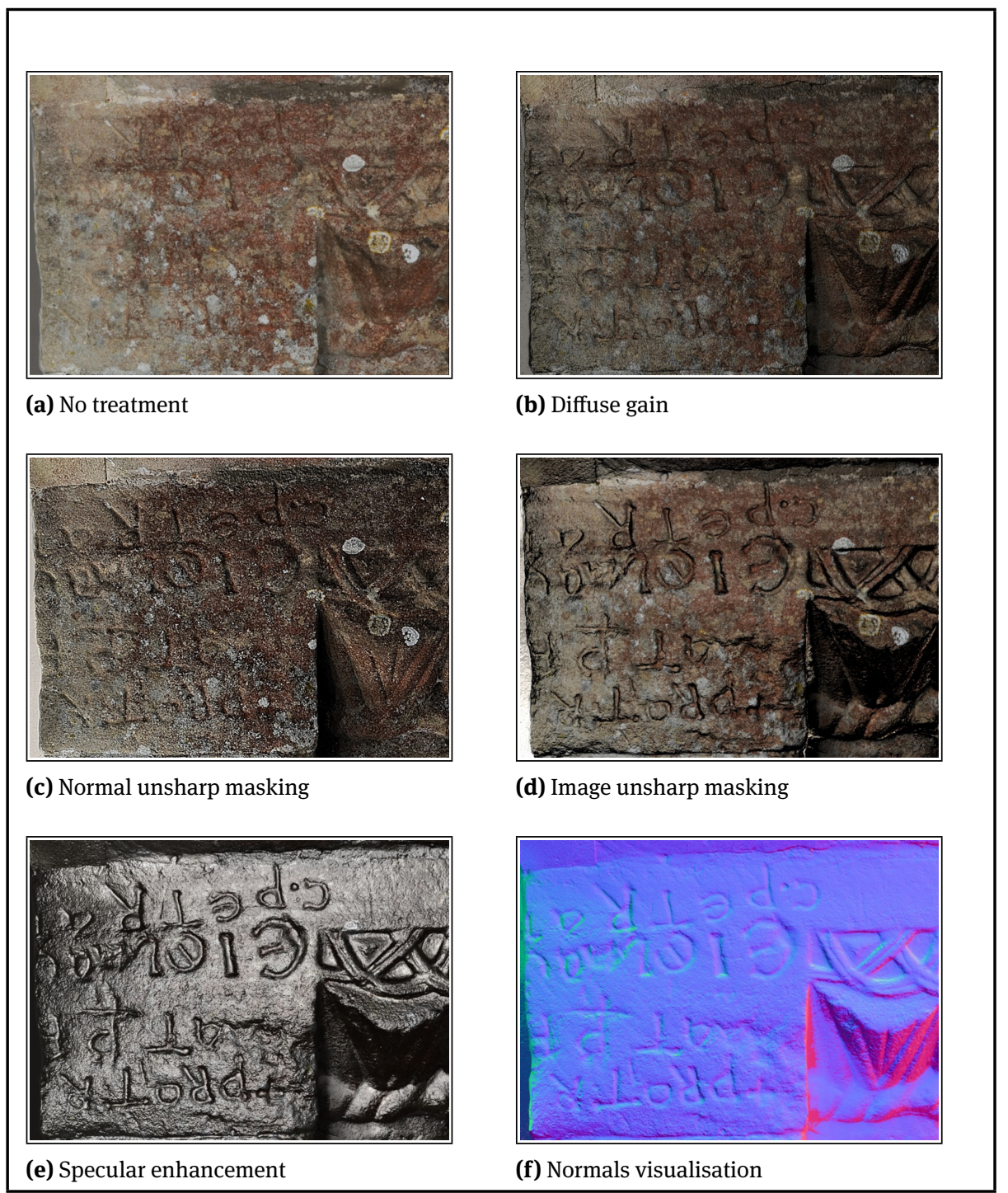

Figure 4.3: Results of an RTI from St. Andrew's Church, Holcombe

logical solution is tailored to their requirements. The most commonly requested technology is RTI, as the visually impressive nature of the results are easy to engage with and to interpret. Interestingly, the project team assumed that RTI and photogrammetry would be the most popular of the technologies because the capture process, when seen as part of a demonstration, seems to be the most straightforward and require the least amount of specialised equipment. In fact, in the majority of cases, the group representatives do not enquire as to the nature or details of the capturing process, and the 
simplicity of this part of the methodology is not witnessed until the training is delivered. This is representative of the significance of the outputs of technological solutions being easily readable, as these seem to be the factors that impact on the decision for take-up, rather than the ease of recording being a deciding factor.

\subsubsection{Decentralised Approach}

From the outset, the OuRTI team encourages a decentralised approach to organisation of the sub-project. The importance of knowledge of photography is emphasised so that each case study is aware from the outset that the involvement of someone with photography experience will be useful. Whilst not essential, this involvement is emphasised at the first conversations between the OuRTI team and the church representatives. The project team acknowledge from the beginning of the project that they are merely acting as facilitators between the technological solutions and the church representatives. Recognising the specialisms already present within the sub-project is an essential part of the project. This motivation is two-fold.

\subsubsection{Project Sustainability}

Firstly, the project methodology must be sustainable. As OuRTI is managed by a small team of archaeologists who are employed elsewhere, the project is unable attend in order to train and then support every church-based group in the UK to use computational photography techniques. But a major aim of the project is that every churchbased project is able to do this. This means that alternative approaches needed to be identified in order to make this possible.

\subsubsection{Recognising Skills}

Secondly, there is a latent resource present in the form of special interest groups in the UK which have skills that could contribute in a very real way to the facilitation of computational photography for church recording. These groups are a resource that is currently under used, and the OuRTI project identified very early on that these groups could provide technical support that was not possible from the initiating project team. Models such as the online crowdsourcing of data interpretation by organisations such as Ancestry.com and large national cultural heritage institutions such as the Victoria and Albert Museum, illustrate the potential of harnessing the energy and specialist knowledge base of people working at an amateur level (Oomen and Aroyo, 2011; Smith-Yoshimura et al., 2012). The BBC and Public Catalogue Foundation (PCF) managed Your Paintings project provides an excellent example of this as it allows for ad- 
vanced annotations to the crowdsourced metadata being collected around images in the collection. Your Paintings is digitising and sharing online images of oil paintings held in collections across the UK (Greg, 2011). The Your Paintings Tagger tool is part of the project and aims to improve the discovery possibilities of the data being collected by crowdsourcing metadata from online contributors. The tags being collected range from the identification of basic attributes such as colour and easily identifiable components, to allowing users with specialisms such as art historians, or with specific knowledge about aspects contained within the images, like architectural details or period costume details, to contribute more advanced data relating to the images.

The Your Paintings project recognises that there are skills that are not directly related to the analysis of oil paintings but that can contribute to improving the data around the images. In the same way, OuRTI aims to harness the skills of community members who have not necessarily identified in the past with the archaeology of churches, but who have an interest in a particular technology that could support work being done. The two key groups for the Re-reading the British Memorial project are photography enthusiasts and those involved in careers or hobbies that include the use of computers. The OuRTI team make use of the fact that technology can attract new people to projects for which they do not immediately identify an interest. In the instance of the OuRTI project, the case studies' use of computational photography techniques to carry out the tasks that were necessary for the recording, interpretation or dissemination projects that were being undertaken drew in additional participants. At one church, a husband of a local history group came to learn how to install and use the RTIBuilder and RTIViewer software. In another location, younger friends of a project participant visited the church to find out how to expand their knowledge of digital photography to incorporate the techniques being taught. Frequently, locally based individuals have visited recording projects whilst they have been occurring in order to find out more about a technology that they had heard was being demonstrated. In many cases, these individuals remain a part of the recording project.

The project also identified that there are instances in which some aspects of a person's knowledge base that may be thought of as exclusionary, could in fact turn out to be an essential component in leading to the community at a church thriving and expanding. For example, at one location two individuals in the group were reluctant to participate as they had no experience in using digital cameras. There was a concern from the group as a whole that this may slow down the learning process for the creation of RTIs. It was not long into the morning's workshop that it became clear to all in the room that the two individuals had been keen photographers in their youth, and that this had led to a good grounding in the principles of analogue photography as they had used film SLR cameras for many years. These two group members were much quicker to understand the methods being employed in the setting up of the camera to record a highlight RTI and showed other members how to use the manual settings on the digital SLR cameras, such as adjusting exposure, aperture and shutter speeds.

Including new user groups within the case studies for the OuRTI has led to the 
technologies being used in unanticipated ways. Local history groups, digital photography groups and software specialists have all engaged with the technologies in different ways. Combining these skills in each case study and supporting the use of the technologies for research questions as defined by those groups rather than by the OuRTI team, has allowed for extensive and detailed user testing to occur. The project draws upon each individual involved in each case study in different ways, and works to allow for a flexible methodology design for every instance of the project at each church. No two case studies are the same, the requirements of the community are different and it is therefore taken as a given that the requirements of the technology will also be different. The team avoids making assumptions about the ways in which the technologies will be used, and in so doing avoids taking a technologically deterministic approach to applying technologies to the problem.

\subsubsection{Re-Reading the British Memorial Project Conclusions}

There is a tendency in software development to focus on the importance of the relevance, the usability, and therefore identification of the value of software. The appropriateness is indeed important, and we see in the instance of the RTI for cultural heritage community that there is a bias towards making the software 'better', with incrementally improving user interfaces with each software release. The OuRTI project has found that an alternative approach is to identify potential new community users, who have an advanced understanding of the nuances of their own specialist area and its requirements. If the appropriate technology and the appropriate support mechanisms are put in place to allow for use of the technology, then these individuals will modify their own practice to make use of the technology that is available, whilst also contributing in a real way to the development of the software. This is a further form of user testing and one that pushes the technology to it limits but from all directions, resulting in new and exciting uses of the software or hardware that could not have been predicted by the originating community.

\subsection{Conclusion}

The availability of open source imaging technologies has the potential to have a significant impact on conventional archaeological practice. The low costs associated with the use of these techniques mean that they are available to virtually all archaeological researchers who have access to a camera and a computer. Beyond issues of cost, the open source development model also creates the possibility of tools and methodologies which are developed by archaeological researchers with archaeological research in mind. This overturns the traditional model of technical adoption in archaeology which has required archaeologists to adopt technologies developed for other appli- 
cations. Not only then are these tools available, they have the capacity to be highly relevant and useable.

However, as outlined above it is not enough simply to make tools available and to assume that people will locate them, acquire them and learn to use them. Skill levels, restrictions on resources and perceptions regarding the capabilities of technology can all prevent the full potential of these tools from being realised. In order to capitalise on the availability of free or cheap digital imaging methods it is essential that methodologies are developed which take into account the requirements and perceptions of specific user communities.

This paper has demonstrated, through the presentation of two case studies, the flexibility and diversity of approach which is required in order to assure adoption by two very different communities of researchers. The projects described here demonstrate the degree of methodological innovation and creativity which can occur when digital imaging technologies are used in conjunction with existing techniques and in dialogue with communities of specialists. In both cases these researchers not only enthusiastically embraced these technologies and new ways of working in the area of archaeological imaging, they also contributed to the development of methodologies and the training of other researchers.

In order to ensure that digital imaging techniques are widely adopted it is important to make sure that they are not just theoretically available to groups who might benefit from their use but that they are also accessible. The development of methodological approaches which specifically enable particular groups to engage with and use digital imaging technology has been highly successful both as a means of promoting the use of these tools and also further refining and developing methodologies which improve the user experience of future users. The involvement of different communities of practice has, as detailed in the case studies above, served to ensure that the limits and capabilities of the techniques are explored.

\section{Bibliography}

Allen, D., Beale, N., Elmer, C., Jones, J., Strutt, K., Beale, G., Allen, C. and Jones, D. (2013), 'Basing house spring-summer 2013: Interim report', Hampshire County Council and University of Southampton. URL: http://basinghouseproject.org/2014/02/21/interim-2013-intro/

Beale, N. and Beale, G. (2012), 'The potential of open models for public archaeology', Digital Futures 2012 (DE2012).

Beale, N., Beale, G., Dawson, I. and Minkin, L. (2013), 'Making digital: Visual approaches to the digital humanities', Electronic Visualisation and the Arts (EVA 2013) pp. 240-247.

Downing, J., Murray, A. A. and Harvey, A. R. (2012), Low-cost multi-spectral imaging camera array, in 'Computational Optical Sensing and Imaging', Optical Society of America, pp. JW1A-6.

Free Software Foundation (2012), 'Various licenses and comments about them', GNU Operating System.

URL: http://www.gnu.org/licenses/license-list.html 
Greg, A. (2011), 'Your paintings: public access and public tagging', Journal of the Scottish Society for Art History 16, 48-52.

Hars, A. and Ou, S. (2001), Working for free? motivations of participating in open source projects, in 'System Sciences, 2001. Proceedings of the 34th Annual Hawaii International Conference on', IEEE, pp. 9-pp.

Huizingh, E. K. (2011), 'Open innovation: State of the art and future perspectives', Technovation 31(1), 2-9.

Jordan, J. and Angelopoulou, E. (2010), Gerbil-a novel software framework for visualization and analysis in the multispectral domain, in 'Vision, Modeling, and Visualization (2010)', The Eurographics Association, pp. 259-266.

Kautz, K. (2011), 'Investigating the design process: participatory design in agile software development', Information Technology \& People 24(3), 217-235.

Kelley, J. H. (1963), 'Some thoughts on amateur archaeology', American Antiquity pp. 394-396.

Levine, P. (2003), The Amateur and the Professional: Antiquarians, Historians and Archaeologists in Victorian England 1838-1886, Cambridge University Press.

Moshenska, G. (2010), 'What is public archaeology?', Present Pasts 1.

Mudge, M., Schroer, C., Earl, G., Martinez, K., Pagi, H., Toler-Franklin, C., Rusinkiewicz, S., Palma, G., Wachowiak, M., Ashey, M., Matthews, N., Noble, T. and Dellepiane, M. (2010), Principles and practices of robust, photography-based digital imaging techniques for museums, in 'The 11th International Symposium on Virtual Reality, Archaeology and Cultural Heritage, VAST 2010'.

Oomen, J. and Aroyo, L. (2011), Crowdsourcing in the cultural heritage domain: opportunities and challenges, in 'Proceedings of the 5th International Conference on Communities and Technologies', ACM, pp. 138-149.

Open Source Initiative (n.d.), 'The open source definition'. URL: http://opensource.org/osd

Sage, A. P. and Rouse, W. B. (2009), Handbook of systems engineering and management, John Wiley \& Sons.

Schroer, C. and Bogart, J. (2011), 'Reflective transformation imaging: Guide to highlight image processing v1.4', Cultural Heritage Imaging.

URL: http://culturalheritageimaging.org/What_We_Offer/Downloads/rtibuilder/RTI_hlt_ Processing_Guide_v14_beta.pdf

Sillar, B. and Tite, M. S. (2000), 'The challenge of 'technological choices' for materials science approaches in archaeology', Archaeometry 42(1), 2-20.

Smith-Yoshimura, K., Cronin, C., Godby, C. J., Lovins, D. and Raine, H. (2012), 'Social metadata for libraries, archives, and museums: executive summary'.

Suchman, L. (1993), 'Working relations of technology production and use', Computer Supported Cooperative Work 2(1-2), 21-39.

Taylor, B. (1995), 'Amateurs, professionals and the knowledge of archaeology', British Journal of Sociology pp. 499-508.

Von Hippel, E. and Von Krogh, G. (2003), 'Open source software and the "private-collective” innovation model: Issues for organization science’, Organization science 14(2), 209-223.

Wheatley, D., Earl, G. and Poppy, S. (2002), Contemporary themes in archaeological computing, Oxbow Books. 